\title{
Features and applications of a field imaging chlorophyll fluorometer to measure stress in agricultural plants
}

\author{
Alexander I. Linn ${ }^{1}$ D $\cdot$ Alexander K. Zeller ${ }^{1} \cdot$ Erhard E. Pfündel $^{2} \cdot$ Roland Gerhards $^{1}$
}

Accepted: 15 October 2020 / Published online: 27 October 2020

(c) The Author(s) 2020

\begin{abstract}
Most non-destructive methods for plant stress detection do not measure the primary stress response but reactions of processes downstream of primary events. For instance, the chlorophyll fluorescence ratio $\mathrm{F}_{\mathrm{v}} / \mathrm{F}_{\mathrm{m}}$, which indicates the maximum quantum yield of photosystem II, can be employed to monitor stress originating elsewhere in the plant cell. This article describes the properties of a sensor to quantify herbicide and pathogen stress in agricultural plants for field applications by the $\mathrm{F}_{\mathrm{v}} / \mathrm{F}_{\mathrm{m}}$ parameter. This dedicated sensor is highly mobile and measures images of pulse amplitude modulated (PAM) chlorophyll fluorescence. Special physical properties of the sensor are reported, and the range of its field applications is defined. In addition, detection of herbicide resistant weeds by employing an $\mathrm{F}_{\mathrm{v}} / \mathrm{F}_{\mathrm{m}}$-based classifier is described. The PAM-imaging sensor introduced here can provide in-field estimation of herbicide sensitivity in crops and weeds after herbicide treatment before any damage becomes visible. Limitations of the system and the use of a classifier to differentiate between stressed and non-stressed plants based on sensor data are presented. It is concluded that stress detection by the $\mathrm{F}_{\mathrm{v}} / \mathrm{F}_{\mathrm{m}}$ parameter is suitable as an expert tool for decision making in crop management.
\end{abstract}

Keywords Chlorophyll fluorescence - Classifier - Decision support system - Plant stress · Pulse amplitude modulating fluorometer

\section{Introduction}

With the need to reduce pesticide use in agriculture while maintaining high yields and food quality, the precise monitoring of crop physiological status is gaining increased importance. In the past four decades, several optical sensor systems have been developed to support farmers and consultants by identifying crop stress response to fungal infections and diseases, weed competition and pests (Peteinatos et al. 2016). Sensors have also been used to detect phytotoxic side effects of pesticides, mainly herbicides in crops (Weber et al.

Alexander I. Linn

alinn@uni-hohenheim.de

1 Department of Weed Science, Institute of Phytomedicine, University of Hohenheim, Stuttgart, Germany

2 Heinz Walz GmbH, Effeltrich, Germany 
2017). Pests, fungal diseases and weeds can be controlled with lower pesticide rates, when they are detected at an early stage of development. However, selection of the best pesticide is very difficult due to the worldwide emergence of resistant populations of weeds, fungi and pests to pesticides. These challenges call for new sensor systems allowing rapid and early plant stress detection under field conditions.

Spectrometers measuring the reflected part of radiation determine the physiological status of the plants non-intrusively (Pascua et al. 2019). This type of sensor employs established relationships between reflected radiation and biochemical and structural properties of plants (Knipling 1970; Xue and Su 2017). Generally, reflectance spectra of non-stressed plants are characterized by low values in the visible range due to high absorbance from plant pigments such as chlorophylls and xanthophylls, and high reflectance in the near infra-red (NIR) range where these pigments do not absorb (Blackburn 2006). Often, in stressed plants, decreased pigment concentrations increase visible reflectance.

For plant stress detection by reflectance data, indices have been introduced which combine specific ranges of reflected visible light and employ NIR wavelengths as reference (Govender et al. 2009; Peteinatos et al. 2016). The best known index is the normalized difference vegetation index (NDVI) (Rouse et al. 1973). Indices such as the photochemical reflectance index (PRI) positively correlate with photosynthetic efficiency (Gamon et al. 1992).

Since standard spectrometers do not provide spatial information, the stress affecting only small parts of the observed area may not be detected. To detect disease spots in an apparently healthy region, imaging spectrometers such as multi-spectral cameras, hyperspectral cameras and line scanners have been developed (Bauriegel and Herppich 2014; Lowe et al. 2017).

Spatial information is also obtained by thermal imaging sensors (Vadivambal and Jayas 2011). They measure infra-red radiation by special detectors and display the originally greyscale images in pseudo-color. The spatial and spectral resolution of thermal cameras is high enough to detect small spots of higher or lower leaf temperature. Higher temperatures of living plant tissue are often associated with lower transpiration and might indicate a fungal infestation (Lindenthal et al. 2005). In necrotic leaf tissue, leaf temperature is often lower. A suitable parameter to separate healthy from diseased crop canopies is the maximum temperature variation (Oerke and Steiner 2010).

The present paper focusses on another imaging sensor, which is based on measurements of chlorophyll fluorescence. Chlorophyll fluorescence, together with heat, represents losses of light energy absorbed by the photosynthetic apparatus (Baker 2008). In pre-darkened leaves, the emission of fluorescence ranges between 2 and $10 \%$ of the absorbed light depending on the state of photosystem II (PS II, Trissl et al. 1993). A relationship between the intensity of chlorophyll fluorescence and the state of photosynthesis has already been observed by Kautsky and Hirsch (1931). In such experiments, sudden light exposure of a leaf first increases chlorophyll fluorescence within a second which then drops off slowly within a few minutes. The initial rise is believed to reflect the transition from open to closed PS II reaction centers, that is, from a photochemically competent state to a state in which light energy cannot be utilized for photochemistry (Schreiber et al. 1995).

In PS II, light-driven charge separation by the reaction center initiates photochemistry. This reaction follows electron transfer via pheophytin to $\mathrm{Q}_{\mathrm{A}}$, a plastoquinone molecule bound to the PS II reaction center (Loll et al. 2005). In the presence of reduced $\mathrm{Q}_{\mathrm{A}}{ }^{-}$, the PS II reaction center is closed because it cannot use excitation energy for stable charge separation (Hankamer and Barber 1997). Usually, the $Q_{A}$ is quickly re-oxidized by electron transfer to $\mathrm{Q}_{\mathrm{B}}$ of the reaction center which, after a second reduction, is exchanged by an 
oxidized $\mathrm{Q}_{\mathrm{B}}$ of the photosynthetic electron transport chain. Very strong (saturating) light intensities result in reduction of this $\mathrm{Q}_{\mathrm{B}}$ pool so that $\mathrm{Q}_{\mathrm{A}}{ }^{-}$re-oxidation stops and PS II reaction centers remain closed (Schreiber et al. 1995).

The competition for excitation energy between fluorescence emission and photochemistry explains why minimum fluorescence $\left(\mathrm{F}_{\mathrm{o}}\right)$ is observed in the dark, that is, in the presence of open PS II reaction centers, but maximum fluorescence $\left(\mathrm{F}_{\mathrm{m}}\right)$ when these reaction centers are closed. Already Kitajima and Butler (1975) have derived that the fluorescence ratio $\mathrm{F}_{\mathrm{v}} /$ $\mathrm{F}_{\mathrm{m}}$ (where $\mathrm{F}_{\mathrm{v}}=\mathrm{F}_{\mathrm{m}}-\mathrm{F}_{\mathrm{o}}$ ) is related to the maximum photochemical efficiency of PS II. Up to now, the $\mathrm{F}_{\mathrm{v}} / \mathrm{F}_{\mathrm{m}}$ parameter has played an important role in plant stress research (Schreiber et al. 1995; Weber et al. 2017; Li et al. 2018; Poudyal et al. 2019).

Using chlorophyll fluorescence analysis to quantify plant stress caused by herbicides is well-established (Macinnis-Ng and Ralph 2003; Follak and Hurle 2004; Bigot et al. 2007; Jin et al. 2010). This application is of general interest because herbicide treatment is the most effective and most frequently used weed control strategy in conventional agriculture (Heap 2014).

An ideal herbicide would selectively kill the weeds but not harm the crop. In reality, even very selective herbicides can harm the crop (Gerhards et al. 2011). Severe damage may occur, when the selectivity of a herbicide is compromised by unfavorable weather conditions, inappropriate timing of the application, wrong rates, and mixtures of active ingredients as well as the addition of adjuvants (Salzman and Renner 1992). Indeed, insufficient selectivity of herbicides has been reported to cause crop biomass reduction and yield losses (Wilson 1999; Wilson et al. 2002; Belfry et al. 2015). The selectivity of a herbicide also depends on the cultivar of the crop plant: for instance, elevated capability to detoxify the active ingredient can reduce the noxiousness of a herbicide for the crop (Smith $\&$ Wilkinson 1974). Clearly, quantifying herbicide stress on both weed and crop is important to assess the usefulness of an herbicide.

Initially, measurements of $\mathrm{F}_{\mathrm{v}} / \mathrm{F}_{\mathrm{m}}$ were confined to specialized laboratories but the commercial availability of pulse amplitude modulated (PAM) fluorometers has made analyses of photosynthesis by measuring $\mathrm{F}_{\mathrm{v}} / \mathrm{F}_{\mathrm{m}}$ and other fluorescence ratio parameters a common analytical tool. To employ PAM fluorometry for detection of plant stress under field conditions, hardware and software modifications of an existing PAM imaging device have been changed. The objective of this study was to introduce the PAM imaging technique as a fast and non-invasive tool to analyze herbicide and pathogen stress and to identify herbicide resistant weeds in the field, which, in future, can be used as an effective tool for decision making in crop management.

\section{Methods}

\section{Hardware of the PAM-sensor}

The PAM-imaging sensor was a mobile MINI Version of the IMAGING-PAM M-Series Chlorophyll Fluorometer (Heinz Walz GmbH, Effeltrich, Germany). The device consists of a waterproof tablet computer, a multi control unit and a measuring unit (labels 1 to 3 in Fig. 1a), where tablet computer and multi control unit are mounted on an aluminum frame with carrying handle. The measuring unit consists of a 1/3" CCD camera $(640 \times 480$ pixels) with K7-MIN (Heinz Walz GmbH, Effeltrich, Germany) prime lens $(\mathrm{F} 1.4 / \mathrm{f}=16 \mathrm{~mm})$ and an LED array arranged around the camera 

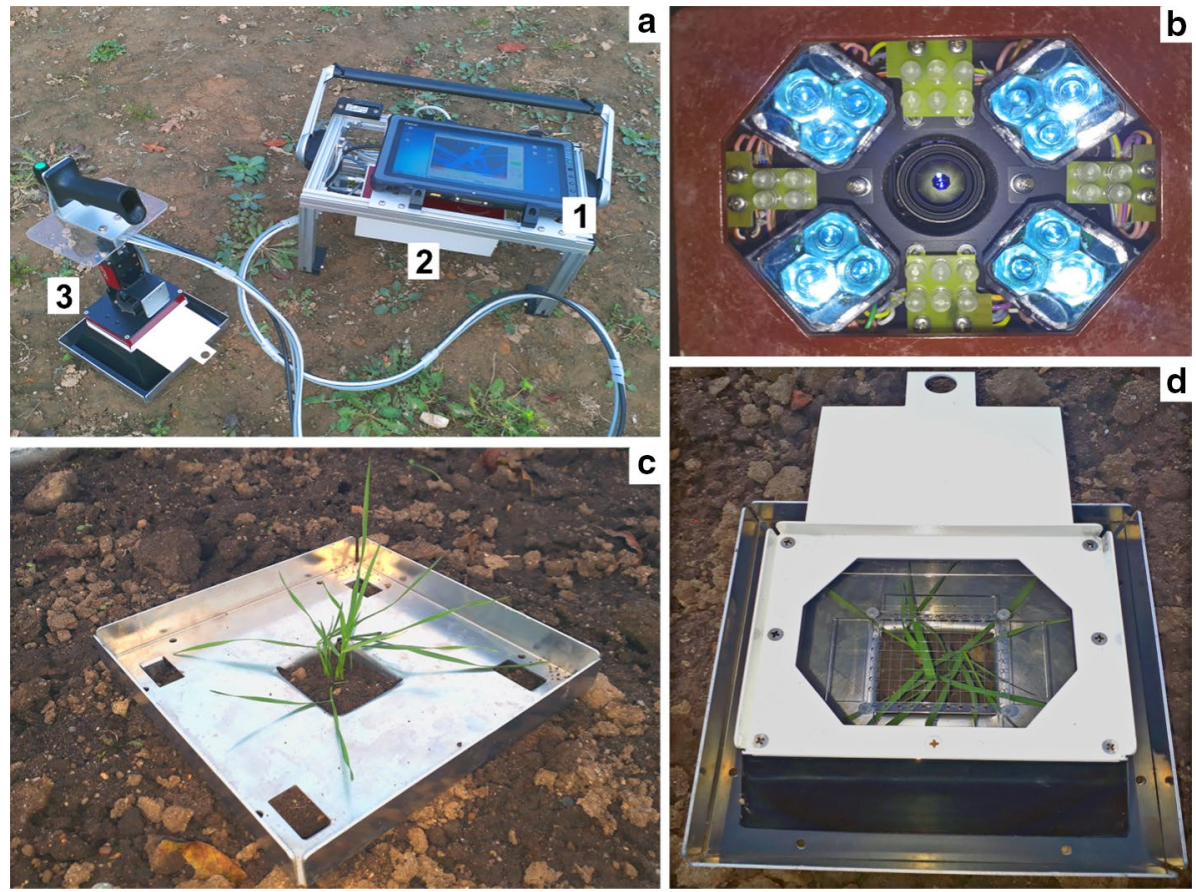

Fig. 1 Overview of the hardware and accessories of the new PAM-imaging system. a Tablet computer (1), control unit (2) and measuring unit (3). b Measuring head with blue light emitting diodes and central camera lens. c Aluminum frame with target plant. d Blackout box

lens. The LED array consists of 12 blue (470 nm) LEDs (Fig. 1b) that deliver both the pulse-modulated excitation light and the saturation pulse which drives the fluorescence rise from $F_{o}$ to $F_{m}$. The LEDs are equipped with a bandpass filter (BG39, Heinz Walz $\mathrm{GmbH}$, Effeltrich, Germany) to prevent their weak long-wavelength emission from reaching the detector. A long pass filter is mounted in front of the camera transmitting only fluorescence radiation and excluding wavelengths below $640 \mathrm{~nm}$. The captured fluorescence is digitized in the camera which is connected to the tablet computer via Ethernet. The multi control unit contains a microcontroller and a rechargeable Li-Ion battery (14.4 V/6 Ah) powering camera and LEDs.

To dark-acclimatize plants for $\mathrm{F}_{\mathrm{o}}$ measurements, blackout boxes $(\mathrm{L} \times \mathrm{W} \times \mathrm{H}=0.1$ $9 \mathrm{~m} \times 0.19 \times 0.8 \mathrm{~m})$ were designed. The bottom of the box forms an aluminum frame whose center is placed above the target plant (Fig. 1c). The frame features spikes for a firm fit on ground and a seat for the upper parts of the box. The box walls are formed by a deep-drawn plastic piece having the shape of a truncated pyramid. The top of the box can be sealed against light by a slider and it also functions as a socket for the measuring unit (Fig. 1d). A Nylon net is mounted $35 \mathrm{~mm}$ above ground to keep larger plants in the focal range of the camera. The measuring area is $24 \times 32 \mathrm{~mm}^{2}$. Dark acclimatization of the plants is done in the blackout boxes with closed slider for at least $20 \mathrm{~min}$. After positioning the measuring unit on the box, the slider is opened, so that fluorescence can be measured with the still dark-acclimatized plant. 


\section{PAM fluorescence and saturation pulse analysis}

The PAM-imaging sensor measures only the fluorescence excited by $\mu$ s flashes of probing light. The effective intensity of these measuring flashes is very weak so that virtually all PS II reaction centers remain open. Under such conditions, $\mathrm{F}_{\mathrm{o}}$ fluorescence is measured. To close the PS II reaction centers and, thus, elicit $\mathrm{F}_{\mathrm{m}}$ fluorescence, the PAM-imaging sensor applies a high intensity pulse of several hundreds of ms length and of $8200 \mu \mathrm{mol} \mathrm{m}^{-2} \mathrm{~s}^{-1}$ photosynthetic photon flux density (wavelength $470 \mathrm{~nm}$ ). The fluorescence ratio of $\mathrm{F}_{\mathrm{v}} / \mathrm{F}_{\mathrm{m}}$ is a measure for the maximum quantum yield of primary PS II photochemistry. In healthy condition, the value for most higher plants [all plants possessing roots, shoots, and leaves (Sitte et al. 1998)] is between 0.78 and 0.84 (Stirbet and Govindjee 2011). A lower value indicates decreased performance of PS II photochemistry. This is called photo-inhibition, which is often observed in plants under stress conditions (Abbaspoor and Streibig 2005).

\section{Software}

The software of the PAM-imaging sensor is based on the ImagingGigE software for IMAGING-PAM fluorometers (Heinz Walz GmbH, Effeltrich, Germany). The software acquires images of $640 \times 480$ pixels for $F_{o}$ and $F_{m}$ level fluorescence of the same sample. From these images, an image of $\mathrm{F}_{\mathrm{v}} / \mathrm{F}_{\mathrm{m}}$ is created by pixelwise calculations. The originally greyscale image of $\mathrm{F}_{\mathrm{v}} / \mathrm{F}_{\mathrm{m}}$ is converted into colored information using a false color scale. The false color scale results from stepwise increasing the angular position around the axis of an HSL (hue, saturation, lightness) color space cylinder where the $\mathrm{S}$ and the $\mathrm{L}$ are kept constant. Figure 2 shows false color images of $\mathrm{F}_{\mathrm{v}} / \mathrm{F}_{\mathrm{m}}$ for a stressed and a non-stressed plant of Stellaria media (L.) Vill. together with the false color scale. The bluish coloration of the non-stressed plant indicates an $\mathrm{F}_{\mathrm{v}} / \mathrm{F}_{\mathrm{m}}$ of about 0.8 (Fig. 2b) which decreased to around 0.4 in the stressed plant (Fig. 2a).

The software allowed export of alphanumeric data as plain text (CSV file) and pictures of $F_{o}, F_{m}$ and $F_{v} / F_{m}$ as TIFF and JPG images. Data handling follows good laboratory practice and does not allow changes of the raw data. Post-processing of data is possible on computers with Windows OS in the offline mode of the software. For post-processing, the area of interest can be assigned manually and several areas can be selected at a time. For each defined area of interest, the arithmetic mean for $\mathrm{F}_{\mathrm{v}} / \mathrm{F}_{\mathrm{m}}$ value is calculated automatically by

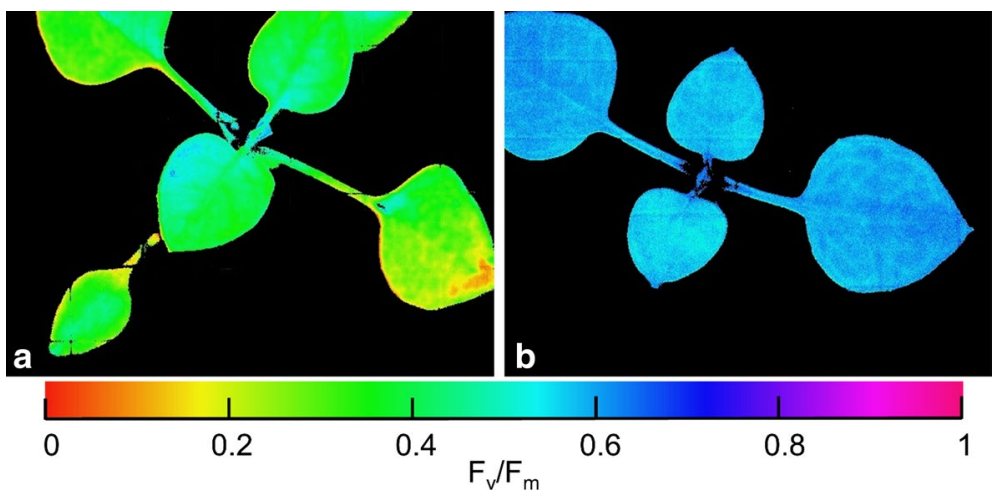

Fig. 2 Images of the $\mathrm{F}_{\mathrm{v}} / \mathrm{F}_{\mathrm{m}}$ parameter of stressed (a) and non-stressed (b) Stellaria media (L.) Vill 
the software. Depending on the size of the sample, an area may represent a whole plant, various leaves or only a leaf part. Post-processing also allows the setting of global upper and lower thresholds for pixel values of $\mathrm{F}_{\mathrm{v}} / \mathrm{F}_{\mathrm{m}}$. Because background fluorescence is often lower than $\mathrm{F}_{\mathrm{o}}$ fluorescence of the target plant, proper setting of the threshold blanks out fluorescing background and, thus, excludes it from $\mathrm{F}_{\mathrm{v}} / \mathrm{F}_{\mathrm{m}}$ calculations. For field use, data management of the ImagingGigE software was modified to permit storage of consecutive $\mathrm{F}_{\mathrm{v}} / \mathrm{F}_{\mathrm{m}}$ measurements in a single file.

The original software disregarded areas exhibiting $\mathrm{F}_{\mathrm{v}} / \mathrm{F}_{\mathrm{m}}$ values close to zero. This software property was designed to distinguish photosynthetic from non-photosynthetic matter. However, strong herbicide action can diminish the $\mathrm{F}_{\mathrm{v}} / \mathrm{F}_{\mathrm{m}}$ of parts of leaves close to zero with the result that these areas are ignored and calculations of the leaf $F_{v} / F_{m}$ become biased towards the less affected leaf regions. In case of grass leaves, this potential difficulty was overcome by implementing an automatic morphological leaf pattern recognition software based on the shape of the leaves. Values of $\mathrm{F}_{\mathrm{v}} / \mathrm{F}_{\mathrm{m}}$ were only recorded for the leaf pixels. For broad-leaved weeds, the pattern recognition is still under development due to the currently still limited data available.

To increase the traceability of measurements, a global navigation satellite system (GNSS) module was implemented writing directly the co-ordinates of the investigated area into the data file. In addition, the camera of the tablet can be used for barcode scanning of a plant sample to assign the sample directly to the measurement. After finishing the measurements, data files can be uploaded automatically to a cloud server via Wi-Fi or LAN connection to the internet. Upload of data to a cloud server was implemented solely with the objective of documentation and sharing of original data. A cloud-based automated postprocessing routine is currently not available.

\section{Applications}

This section gives an overview on experiments performed with the PAM-imaging sensor. The experiments described are summarized in Table 1. Further experimental descriptions can be found in the respective references.

\section{Herbicide induced stress in weeds}

Monitoring of the herbicide efficacy on weeds plays a major role in crop production. The earlier insufficient herbicide action is detected, the sooner additional weed control measures can be applied. In the case of herbicide resistant weeds, timely counter measures following their early detection can reduce the risk of growing resistant populations. Therefore, a strategy of estimating the herbicide efficacy, including the detection of herbicide resistant weeds, was developed in three main steps.

In step 1, weed sensitivity was estimated at the population level by comparing the mean $\mathrm{F}_{\mathrm{v}} / \mathrm{F}_{\mathrm{m}}$ values of herbicide treated and untreated Alopecurus myosuroides Huds. Plants (EXP1, EXP2, EXP3, Table 1). In the second step, the $\mathrm{F}_{\mathrm{v}} / \mathrm{F}_{\mathrm{m}}$ values of susceptible and unsusceptible single plants were separated post-hoc to investigate the differences in the $\mathrm{F}_{\mathrm{v}} / \mathrm{F}_{\mathrm{m}}$ values of these two sample types (EXP4, Table 1). In step 3, a classifier was created to assign single plants to the classes "sensitive" and "resistant" based on their $F_{v} / F_{m}$ value. Ideally, this classifier should identify herbicide resistance without untreated reference plants (EXP5, Table 1). These three steps are explained in more detail in the three subsequent sections. 


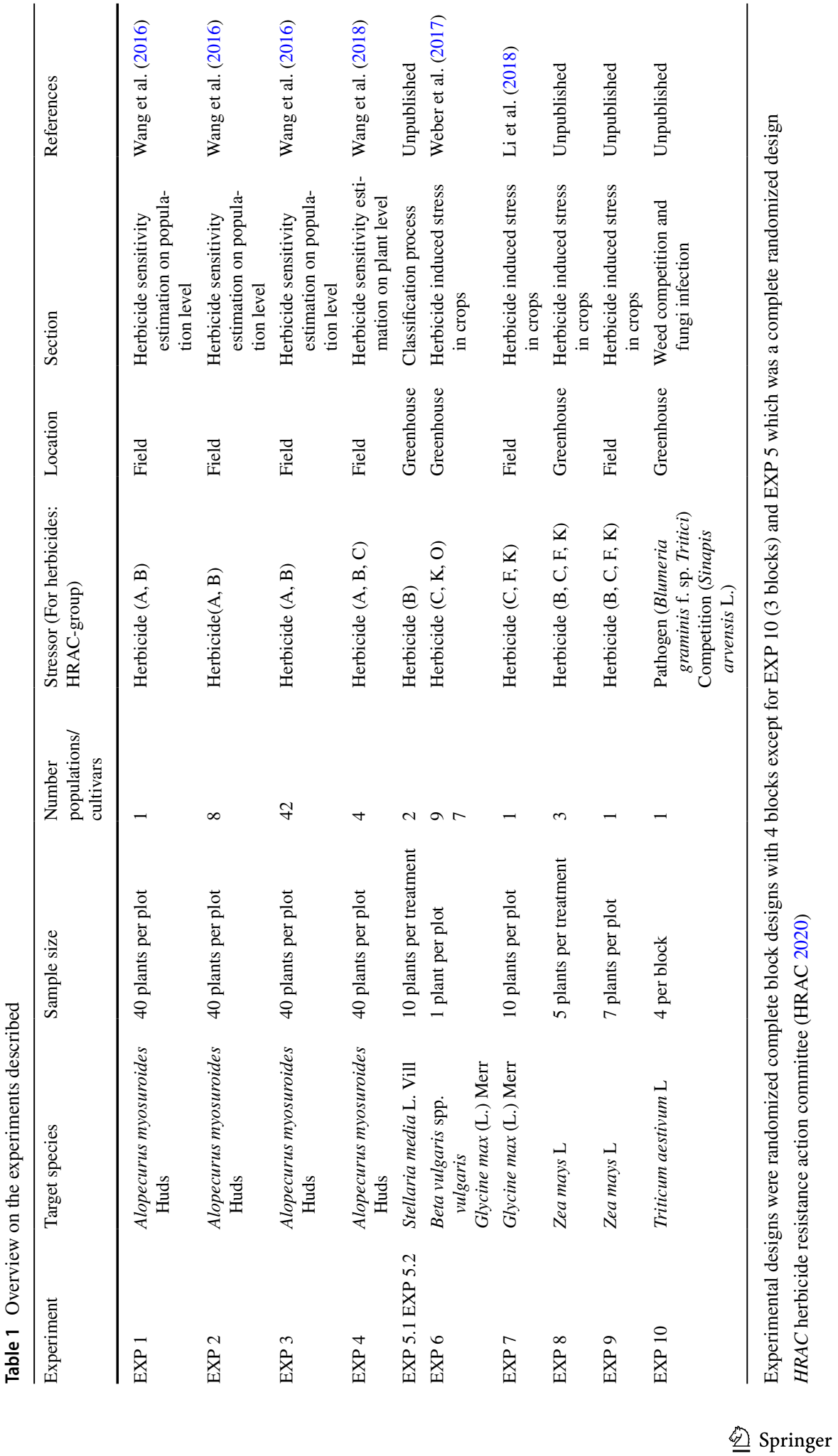




\section{Herbicide sensitivity estimation at population level}

Wang et al. (2016) described the first estimations on herbicide-induced stress in A. myosuroides with the PAM-imaging sensor under field conditions (EXP1, Table 1). This first field experiment formed the basis of later studies with this sensor on herbicide resistance. The authors examine the discrimination of sensitive A. myosuroides plants from untreated plants after treatment with acetolactate synthase (ALS) inhibitors and acetyl-CoA carboxylase (ACCase) inhibitors in a field experiment. The differences in the $F_{v} / F_{m}$ values of the untreated and sprayed plants were evaluated using Tukey's honestly significant difference (HSD) (Abdi and Williams 2010), test per day $(\mathrm{P}<0.05)$ with the result that a discrimination of untreated and treated plants was possible for ALS- and ACCase-inhibiting herbicides from 5 days after treatment (DAT) on.

For the further development of the PAM-imaging system, two large-scale field trials were carried out. These trials focused on the distinction between herbicide-resistant and sensitive weed populations (Wang et al. 2016). The first set of experiments was carried out at eight locations in northern and southern Germany with the fields' native A. myosuroides populations (EXP2, Table 1). For the second experiment, 42 A. myosuroides populations with known resistance status were sown into a winter wheat field at one site (EXP3, Table 1). Plots of 40 plants were evaluated. In both experiments, untreated plants of each population were included and each population was treated with ALS and ACCase inhibiting herbicides. Visual and fluorometric assessment was 21 and 5 days after treatment, respectively. Visual assessment was based on the proportion of surviving plants. The PAM-imaging sensor was used for fluorometric assessment measuring the $F_{v} / F_{m}$ values. In the visual assessment, $\mathrm{R}$ represents the summarized groups of slightly resistant (80-73\% dead), moderate resistant ( $72-37 \%$ dead), and strongly resistant (36-0\% dead). The $\mathrm{F}_{\mathrm{v}} / \mathrm{F}_{\mathrm{m}}$ value-based classification of the populations (arithmetic mean of 40 plants plot $^{-1}$ Tukey's HSD test, $\mathrm{P}<0.05$ ) was clearly supported by the proportion of dead and alive plants 21 DAT (Table 2).

The findings of these experiments (EXP1, EXP2, EXP3) (Wang et al. 2016) stated that the $\mathrm{F}_{\mathrm{v}} / \mathrm{F}_{\mathrm{m}}$ value obtained from 40 untreated and 40 herbicide-treated plants gave reliable information about their resistance status with a high accuracy of $88 \%$ (Table 2). That this decision protocol misses some resistant populations might be caused by temporary decrease of $\mathrm{F}_{\mathrm{v}} / \mathrm{F}_{\mathrm{m}}$ in populations which later recovered from herbicide treatment. It is obvious that this in-season in-field herbicide resistance classification is only applicable if untreated control plants are present, which is typically not the case under practical field conditions. Moreover, herbicide resistance is estimated on a population level without

Table 2 Confusion matrix of visually and fluorometrically assessed herbicide resistance of Alopecurus myosuroides Huds. populations after treatment with acetolactate synthase and acetyl-coA carboxylase inhibitors, respectively

\begin{tabular}{llr}
\hline & Visual assessment & $\mathrm{R}$ \\
\cline { 3 - 3 } & $\mathrm{S}$ & \\
\hline PAM-imaging sensor & & 11 \\
$\mathrm{~S}$ & 27 & 58 \\
$\mathrm{R}$ & 0 & \\
\hline
\end{tabular}

$S$ sensitive, $R$ resistant. (Wang et al. 2016) 
precise information about the frequency of resistant plants. To overcome these limitations, the $F_{v} / F_{m}$ values of individual sensitive and resistant plants were examined.

\section{Herbicide sensitivity estimation at plant level}

This developmental step focused on $\mathrm{F}_{\mathrm{v}} / \mathrm{F}_{\mathrm{m}}$ values of individual plants with the objective to assess the degree of herbicide action without controls and, thus, to increase the scope of application of the PAM-imaging sensor (Wang et al. 2018). At three field sites, A. myosuroides plants were treated with ALS, ACCase and PS II inhibitors (EXP4, Table 1). The $\mathrm{F}_{\mathrm{v}} / \mathrm{F}_{\mathrm{m}}$ value of each single plant was assigned post-hoc to the two groups "resistant" and "sensitive". Per treatment, differences between these two groups were identified per measurement day using Tukey's HSD test $(\mathrm{P}<0.05)$. The correct classification in resistant and sensitive plants was already possible at 3 DAT for all treatments without comparing the $\mathrm{F}_{\mathrm{v}} / \mathrm{F}_{\mathrm{m}}$ of treated plants with untreated controls. Similar results were found by Wang et al. (2017) in Apera spica-venti (L.) Beauv. Although the assignment of plants and their respective $\mathrm{F}_{\mathrm{v}} / \mathrm{F}_{\mathrm{m}}$ values was carried out after the results on resistance were present, these experiments demonstrated the possibilities of using the PAM-imaging system at the single plant level.

\section{Classification process}

In the last development step, the concept of assigning (classifying) a single plant to the groups (classes) "resistant" and "sensitive" based on its $\mathrm{F}_{\mathrm{v}} / \mathrm{F}_{\mathrm{m}}$ value was investigated. For this, a greenhouse experiment was set up as a randomized complete design and repeated twice (EXP5.1, EXP5.2, Tables 1 and 3). Sensitive and resistant Stellaria media (L.) Vill. (STEME-S, STEME-R) plants were treated in the 6-8 leaf stage with three different ALS inhibiting herbicides at recommended application rates (Table 3). The $F_{v} / F_{m}$ values of 10 plants per biotype and treatment were examined 4 DAT.

The classification into the two classes "resistant" and "sensitive" was done using a discriminant maximum likelihood classifier (Huberty and Olejnik 2006). After training the classifier for those two classes, each measured $\mathrm{F}_{\mathrm{v}} / \mathrm{F}_{\mathrm{m}}$ value was assigned to the most probable class. Furthermore, the training was performed with data of EXP 5.1 and the testing was done with data of EXP 5.2, and vice-versa. For each classifier, the accuracy was calculated. To compare the results of the classifiers with results of the previous data evaluation process (see text Sect. Herbicide sensitivity estimation at population level), differences

Table 3 Herbicides utilized in experiments on herbicide-induced stress in Stellaria media (L.) Vill

\begin{tabular}{llllll}
\hline Trade name & $\begin{array}{l}\text { Active ingredients } \\
\text { rate }\end{array}$ & Formulation & Application rate & HRAC-group & Provider \\
\hline Allie® SX® & $\begin{array}{c}200 \mathrm{~g} \mathrm{~kg}^{-1} \text { Metsul- } \\
\text { furon }\end{array}$ & $\mathrm{SG}$ & $40 \mathrm{~g} \mathrm{ha}^{-1}$ & $\mathrm{~B}$ & Du Pont de Nemours \\
Pointer@ SX® & $\begin{array}{c}500 \mathrm{~g} \mathrm{~kg}^{-1} \text { Tribenu- } \\
\text { ron }\end{array}$ & $\mathrm{SG}$ & $40 \mathrm{~g} \mathrm{ha}^{-1}$ & $\mathrm{~B}$ & DuPont de Nemours \\
Primus@ & $50 \mathrm{~g} \mathrm{l}^{-1}$ Florasulam & $\mathrm{SC}$ & $0.11 \mathrm{ha}^{-1}$ & $\mathrm{~B}$ & Dow Agroscience \\
\hline
\end{tabular}

(EXP 1.1, EXP 1.2, see text Sect. Classification process)

HRAC herbicide resistance action committee (HRAC 2020), SC suspension concentrate, $S G$ water soluble granules 
in the $\mathrm{F}_{\mathrm{v}} / \mathrm{F}_{\mathrm{m}}$ value between the populations were compared using the Tukey's HSD test $(\mathrm{P}<0.05)$.

The $F_{v} / F_{m}$ value was always calculated as the arithmetic mean of pixels within an "area of interest". The standard deviation of pixels within an area of interest is small which makes a hypothetical effect of the standard deviation on the accuracy of the classifier unlikely. Moreover, it has been found that determining the area of interest manually or automatically with background fluorescence suppressed to different degrees had only marginal effects on the $F_{v} / F_{m}$ which supports the view that extraction of $F_{v} / F_{m}$ from raw images yields robust data and, thus, is not a critical factor for this classification approach.

None of the herbicide treated STEME-S plants survived the treatment, while all STEME-R plants survived the herbicide treatments until the final visual assessment at 30 DAT. In both experiments, Tukey's HSD test $(\mathrm{P}<0.05)$ attested lower $\mathrm{F}_{\mathrm{v}} / \mathrm{F}_{\mathrm{m}}$ values of STEME-S than of STEME- R after treatment with tribenuron (Table 4). After treatment of florasulam and metsulfuron, the results were inconclusive: Tukey's HSD test discriminated STEME-S and STEME-R by their $\mathrm{F}_{\mathrm{v}} / \mathrm{F}_{\mathrm{m}}$ value in EXP 1.1 but not in EXP 1.2. The classifiers, however, assigned up to $95 \%$ of the plants correctly (Table 4). Likewise, in the cases of florasulam and metsulfuron, the classifiers had quite high accuracies of $70 \%$ to $85 \%$. Hence, the classifier appears to be superior over the decision protocol using Tukey's HSD test, particularly when means of different populations are difficult to distinguish.

Because single plant analysis was carried out with the classifier, the frequency of resistant plants within the population could be determined. Thus, analyses of resistance based on the classifier contain information on the extent of resistant plants of a population which goes beyond the simple classification of entire weed populations as "sensitive" or "resistant". Of course, to become a reliable in-field tool, the classifier should work with even higher accuracies of identification under authentic outdoor conditions.

\section{Herbicide induced stress in crops}

To investigate the phytotoxicity on crop cultivars of commonly used herbicides for weed control in sugar beet (Beta vulgaris spp. vulgaris) and soybean (Glycine max (L.) Merr.), Weber et al. (2017) examined nine sugar beet and seven soybean cultivars with

Table 4 Maximum quantum yield of photosystem II $\left(\mathrm{F}_{\mathrm{v}} / \mathrm{F}_{\mathrm{m}}\right)$ of sensitive (S) and resistant (R) Stellaria media (L.) Vill. plants 4 days after treatment in comparison with the accuracy of the discriminant maximum likelihood classifiers

\begin{tabular}{|c|c|c|c|c|c|c|}
\hline \multirow[t]{3}{*}{ Treatment } & \multicolumn{4}{|c|}{$\mathrm{F}_{\mathrm{v}} / \mathrm{F}_{\mathrm{m}}$} & \multicolumn{2}{|l|}{ Accuracy \% } \\
\hline & \multicolumn{2}{|c|}{ EXP 1.1} & \multicolumn{2}{|c|}{ EXP 1.2} & \multirow{2}{*}{$\begin{array}{l}\text { Train EXP } 1.1 \\
\text { Test EXP } 1.2\end{array}$} & \multirow{2}{*}{$\begin{array}{l}\text { Train EXP } 1.2 \\
\text { Test EXP } 1.1\end{array}$} \\
\hline & $\mathrm{R}$ & $\mathrm{S}$ & $\mathrm{R}$ & $\mathrm{S}$ & & \\
\hline Control & 0.64 & 0.63 & 0.62 & 0.68 & - & - \\
\hline Florasulam & 0.62 & $0.53 *$ & 0.62 & 0.56 & 80 & 85 \\
\hline Metsulfuron & 0.65 & $0.58 *$ & 0.61 & 0.56 & 70 & 70 \\
\hline Tribenuron & 0.65 & $0.55^{*}$ & 0.64 & $0.51 *$ & 85 & 95 \\
\hline
\end{tabular}

The classifiers were based on the single $\mathrm{F}_{\mathrm{v}} / \mathrm{F}_{\mathrm{m}}$ values after training with data of experiment EXP 1.1 and testing with data of EXP 1.2, and vice versa (see text Sect. Classification process)

Values with asterisk indicate statistically significant differences per experiment and population between untreated and treated plants (Tukey's HSD test, $\mathrm{P}<0.05$ ) 
the PAM-imaging sensor directly after herbicide application in the greenhouse (EXP6, Table 1). Depending on the herbicide and cultivar, the $\mathrm{F}_{\mathrm{v}} / \mathrm{F}_{\mathrm{m}}$ values of the herbicidetreated sugar beets were reduced significantly by $15 \%$ to $66 \%$ compared to the untreated control at 1 DAT. In herbicide-treated soybean, the $\mathrm{F}_{\mathrm{v}} / \mathrm{F}_{\mathrm{m}}$ values were decreased by $9 \%$ to $74 \%$ within 9 DAT, depending on the herbicide and cultivar. In both cases, the PAMimaging sensor displayed the phytotoxicity more clearly than a visual phytotoxicity assessment, which was only able to spot small differences in soybean. Li et al. (2018) were able to assess the phytotoxicity of soybean herbicides on soybean with the PAMimaging sensor in the field and found differences in the phytotoxicity of different herbicides (EXP7, Table 1).

The PAM-imaging sensor was also employed to measure herbicide-induced stress in maize (Zea mays L.) in a greenhouse and a field experiment conducted in 2017 (EXP8, EXP9, Table 1, unpublished results). The experiments were aimed to compare herbicide action on various cultivars and to test how various herbicides affect the same cultivar.

The greenhouse experiment was set up as a three-factorial experiment (EXP8, Table 1). The cultivars NK RAVELLO (Syngenta Seeds GmbH, Bad Salzuflen, Germany), RIDLEY (Limagrain GmbH, Edemissen, Germany) and SUSANN (Saaten-Union GmbH, Isernhagen, Germany) were examined. Pots $(176 \times 150 \mathrm{~mm})$ were filled with sandy loam and one seed per pot was placed in a depth of $45 \mathrm{~mm}$. In the four-leaf stage, the plants were sprayed in a precision application chamber with five commonly used herbicides and herbicide tank mixes for weed control in maize (Table 5). The $\mathrm{F}_{\mathrm{v}} / \mathrm{F}_{\mathrm{m}}$ value of single plants was measured 1-7, and 9 DAT. Aboveground dry biomass was evaluated 29 DAT.

Table 5 Treatments in the experiments on herbicide induced stress in maize (Zea mays L.)

\begin{tabular}{llll}
\hline Treatment & Active ingredients rate & HRAC-group & $\begin{array}{l}\text { Application rate }(\mathrm{g} \\
\text { active ingredient } \\
\left.\text { ha }^{-1}\right)\end{array}$ \\
\hline Untreated control & - & - & - \\
MaisTer power & Foramsulfuron $31,5 \mathrm{~g} \mathrm{l}^{-1}$ & $\mathrm{~B}$ & 47.3 \\
& Thiencarbazone $10 \mathrm{~g} \mathrm{l}^{-1}$ & $\mathrm{~B}$ & 15 \\
& Iodosulfuron $1 \mathrm{~g} \mathrm{l}^{-1}$ & $\mathrm{~B}$ & 1.5 \\
Laudis + & Tembotrione $44 \mathrm{~g} \mathrm{l}^{-1}$ & $\mathrm{~F} 2$ & 88 \\
Spectrum & Dimethenamid $720 \mathrm{~g} \mathrm{l}^{-1}$ & $\mathrm{~K} 3$ & 900 \\
Kelvin OD & Nicosulfuron $40 \mathrm{~g} \mathrm{l}^{-1}$ & $\mathrm{~B}$ & 32 \\
Spectrum & Dimethenamid $720 \mathrm{~g} \mathrm{l}^{-1}$ & $\mathrm{~K} 3$ & 576 \\
Maran & Mesotrione $100 \mathrm{~g} \mathrm{l}^{-1}$ & $\mathrm{~F} 2$ & 80 \\
B 235 & Bromoxynil $235 \mathrm{~g} \mathrm{l}^{-1}$ & $\mathrm{C} 3$ & 94 \\
Elumis + & Mesotrione $75 \mathrm{~g} \mathrm{l}^{-1}$ & $\mathrm{~F} 2$ & 93.75 \\
& Nicosulfuron $30 \mathrm{~g} \mathrm{l}^{-1}$ & $\mathrm{~B}$ & 37.5 \\
Peak & Prosulfuron $750 \mathrm{~g} \mathrm{~kg}^{-1}$ & $\mathrm{~B}$ & 15 \\
Arigo + & Mesotrione $360 \mathrm{~g} \mathrm{~kg}^{-1}$ & $\mathrm{~F} 2$ & 90 \\
& Nicosulfuron $120 \mathrm{~g} \mathrm{~kg}^{-1}$ & $\mathrm{~B}$ & 30 \\
Activus SC & Rimsulfuron $30 \mathrm{~g} \mathrm{~kg}^{-1}$ & $\mathrm{~B}$ & 7.5 \\
B 235 & Pendimethalin $400 \mathrm{~g} \mathrm{l}^{-1}$ & $\mathrm{~K} 1$ & 1000 \\
\hline & Bromoxynil $235 \mathrm{~g} \mathrm{l}^{-1}$ & $\mathrm{C} 3$ & 58.75 \\
\hline
\end{tabular}

HRAC herbicide resistance action committee (HRAC 2020) 
The field experiment was set up as a two-factorial experiment (EXP9, Table 1). The cultivar RIDLEY was seeded on 17th of May. The same herbicides as used in the greenhouse experiment were applied with a motorized field plot sprayer (Schachtner Gerätetechnik, Ludwigsburg, Germany) at the four-leaf stage of maize. The $F_{v} / F_{m}$ values of 7 plants per plot were assessed at similar DAT as described in the greenhouse experiment. Aboveground dry biomass was assessed 25 DAT.

In both experiments, a decrease of the $\mathrm{F}_{\mathrm{v}} / \mathrm{F}_{\mathrm{m}}$ value of treated plants was dependent on the herbicides utilized. Especially, herbicide mixtures containing active ingredients with the mode of action in the PS II decreased the $\mathrm{F}_{\mathrm{v}} / \mathrm{F}_{\mathrm{m}}$ values over the first few DAT (Fig. 3, squares). Then, the $\mathrm{F}_{\mathrm{v}} / \mathrm{F}_{\mathrm{m}}$ values recovered with increasing DAT but did not reach the values of the untreated control. In the greenhouse experiment, no differences in the $F_{v} / F_{m}$ values between the three cultivars could be observed. However, all herbicide treated plants had a reduced dry biomass compared to the untreated control. In the field experiment, the untreated control had the lowest biomass, while the biomass between herbicide treated maize did not differ. Possibly, the high weed pressure in the untreated control plots led to this biomass reduction in herbicide untreated maize plants. Based on the $\mathrm{F}_{\mathrm{v}} / \mathrm{F}_{\mathrm{m}}$ data, mixtures without active ingredients interacting directly with the PS II seem to handle maize plants more carefully, while the results on biomass could not emphasize this.

\section{Weed competition and fungi infection}

A two-factorial pot experiment with 3 repetitions was conducted in the greenhouse in 2013 to investigate if the PAM-imaging sensor was capable of detecting early infestation of powdery mildew (Blumeria graminis f. sp. tritici) and weed competition in winter wheat (Triticum aestivum L.), cv. Toras (EXP10, Table 1, unpublished results). Winter wheat was sown on November 07 with 60 seeds in plates of $600 \times 400 \mathrm{~mm}$ filled with a sandy loam. Plants were cultivated at temperatures of $15^{\circ} \mathrm{C}$ during the day $(12 \mathrm{~h})$ and $12{ }^{\circ} \mathrm{C}$ at night $(12 \mathrm{~h})$. Powdery mildew was spray-inoculated at November 26 at 3-leaf stage of wheat with 200,000 spores/ml. Weed competition was initiated with charlock

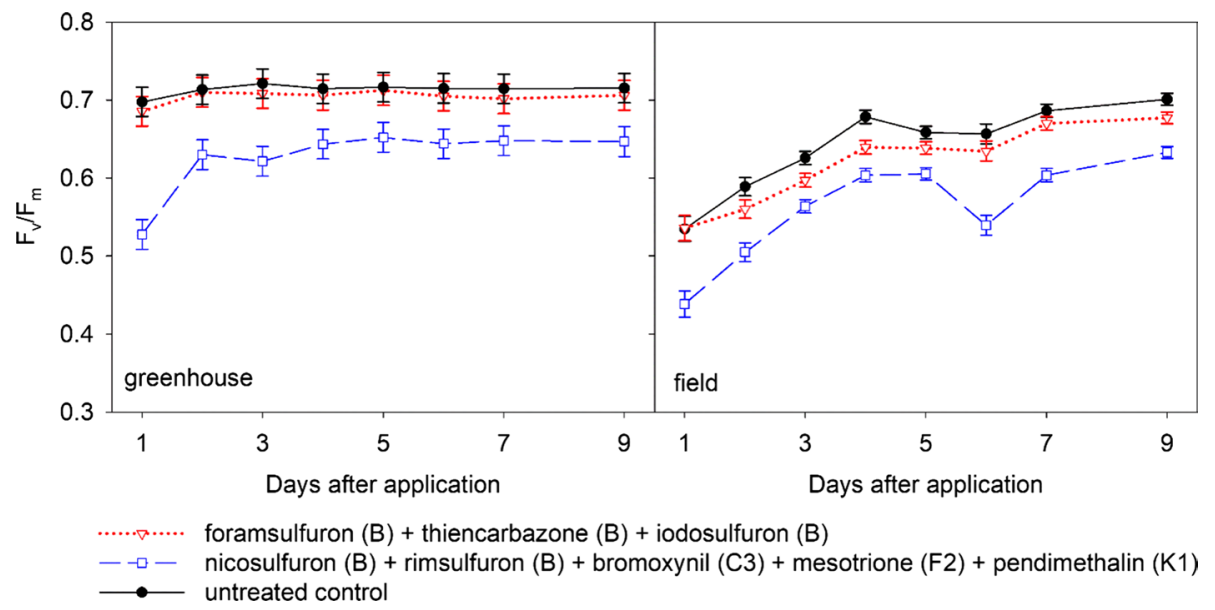

Fig. 3 Variation of maximum photochemical quantum yield of photosystem II $\left(\mathrm{F}_{\mathrm{v}} / \mathrm{F}_{\mathrm{m}}\right)$ of maize (Zea maize L.) after herbicide treatment. Herbicide mode of action is displayed after each herbicide in accordance with classification by the herbicide resistance action committee 
(Sinapis arvensis L.) sown at a density of 50 seeds per plate simultaneously with winter wheat, resulting in an average of 39 emerged weed seedlings per plate.

Visual assessments of disease infestation and $\mathrm{F}_{\mathrm{v}} / \mathrm{F}_{\mathrm{m}}$ measurement (four measurements per plate) with the PAM-imaging sensor were carried out over a period of 30 days after inoculation. Plants were dark adapted for $20 \mathrm{~min}$ before measurement. The first symptoms appeared 13 DAT at 5-leaf stage with an estimated rate of less than $0.1 \%$ infestation. Infestation rate increased to $1.5 \%$ until 16 DAT and $10 \%$ until 19 DAT (first tiller appeared). The combination of weed competition and powdery mildew infection resulted in significantly lower $\mathrm{F}_{\mathrm{v}} / \mathrm{F}_{\mathrm{m}}$ values already 13 DAT compared to untreated control plants, when almost no visual symptoms appeared (Fig. 4). Powdery mildew treatments and the combination of both stresses resulted in significantly lower $\mathrm{F}_{\mathrm{v}} / \mathrm{F}_{\mathrm{m}}$ values at 16 and 19 DAT (Fig. 4). The data supports the view that the PAM-imaging sensor is effective for early detection of fungal disease.
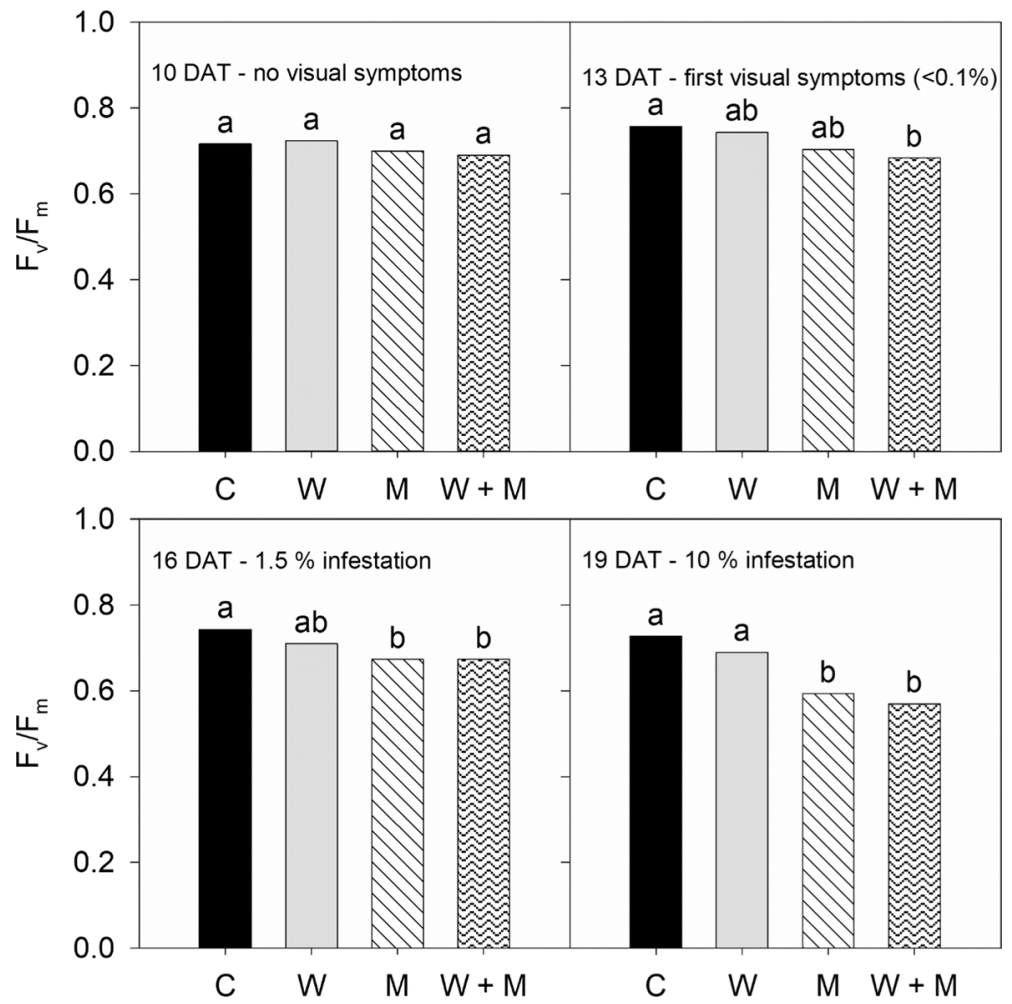

Fig. 4 Maximum photochemical quantum yield of photosystem II $\left(\mathrm{F}_{\mathrm{v}} / \mathrm{F}_{\mathrm{m}}\right)$ of winter wheat $\left(240\right.$ plants $\left./ \mathrm{m}^{2}\right)$. $\mathrm{C}=$ untreated control; $\mathrm{W}=$ winter wheat in competition with Sinapis arvensis $\mathrm{L} .\left(200 \mathrm{plants} / \mathrm{m}^{2}\right) ; \mathrm{M}=$ winter wheat infested with powdery mildew; $\mathrm{M}+\mathrm{W}=$ winter wheat in competition with Sinapis arvensis $\mathrm{L}$. $\left(200\right.$ plants $\left./ \mathrm{m}^{2}\right)+$ winter wheat infested with powdery mildew; DAT = days after inoculation with powdery mildew. Bars with identical small letters do not differ statistically 


\section{Limitations}

PAM fluorometers excite the chlorophyll fluorescence which they are measuring. Therefore, the PAM-imaging sensor is an active sensor which is only capable of assessing plant stress in a narrow field of view close to the target. This excludes remote screening of stress by mounting the sensor on aerial vehicles. Screening of larger areas by a PAM sensor is possible, however, by larger series of measurements distributed over the area in accordance with established sampling patterns.

Chlorophyll fluorescence, especially the $\mathrm{F}_{\mathrm{v}} / \mathrm{F}_{\mathrm{m}}$ value, responds to plant stress of many origins (Rosenqvist and van Kooten 2003). Therefore, it is difficult to unequivocally trace back a decreased value for $\mathrm{F}_{\mathrm{v}} / \mathrm{F}_{\mathrm{m}}$ to a distinct stressor. The association between stress origin and fluorescence is possible, however, if the experiment includes untreated references and obeys the ceteris paribus (all other things being equal) principle.

In the field, agricultural plants are exposed to changing temperatures. Pospíśil et al. (1998) examined chlorophyll fluorescence changes in dark acclimatized leaves of winter barley (Hordeum vulgare L. cv. Akcent) in a laboratory experiment. They found that the $\mathrm{F}_{\mathrm{v}} / \mathrm{F}_{\mathrm{m}}$ value was always close to 0.8 in the temperature range from -10 to $30{ }^{\circ} \mathrm{C}$. Usually, field measurements are performed in this range so that pure temperature effects on $\mathrm{F}_{\mathrm{v}} / \mathrm{F}_{\mathrm{m}}$ can be disregarded.

The situation is different when plants at various temperatures are exposed to sunlight. In the presence of strong light, low or freezing temperatures can induce photoinhibition of PS II which leads to a decreased $F_{v} / F_{m}$ value (Krause 1994). Hence, photoinhibition by light is a potential factor reducing the $\mathrm{F}_{\mathrm{v}} / \mathrm{F}_{\mathrm{m}}$ in addition to herbicide stress. As the effects of photoinhibition are difficult to remove from measured $\mathrm{F}_{\mathrm{v}} / \mathrm{F}_{\mathrm{m}}$ data, experiments testing herbicide stress should be performed under non-photoinhibitory conditions.

\section{Perspectives}

For future applications, the PAM imaging device has been optimized for field and greenhouse studies. While this sensor is a complex tool and an expertise is needed to perform correct measurements and evaluate the data gathered, the PAM imaging sensor has to be seen as an expert tool used by scientists or high-level consultants. Nevertheless, the device has various applications covering integrated weed management, breeding and the development of agrochemicals. In general, it can be used in the field to identify early and objective stress in the target plant. A further improvement of the classifier for herbicide resistance detection in weeds could make the device a reliable in-season tool for herbicide efficacy estimations. In breeding, the sensor could help to select the most favorable cultivar regarding stress tolerance (e. g. herbicide), while for the production of agrochemicals, the effect on plant health status of herbicides, tank mixes, adjuvants and plant tonics could be evaluated in the field.

\section{Conclusion}

The present study reviews the development of a PAM imaging device for stress measurements in agricultural plants. The hardware and accessories of the PAM-imaging sensor have been optimized for experiments in the greenhouse and the field. By measuring the 
simple parameter $\mathrm{F}_{\mathrm{v}} / \mathrm{F}_{\mathrm{m}}$, the PAM-imaging sensor cannot only detect the action of herbicides inhibiting PS II but also of herbicides acting on distant biochemical pathways. Moreover, the $\mathrm{F}_{\mathrm{v}} / \mathrm{F}_{\mathrm{m}}$ also responds to fungi infestation which extends the scope of application of the PAM-imaging sensor. These studies suggest that the PAM-imaging sensor can generally be utilized by breeders and growers to optimize the selectivity of herbicides. Compared to established visual methods, PAM analysis is superior because herbicide stress is analyzed quantitatively by the $\mathrm{F}_{\mathrm{v}} / \mathrm{F}_{\mathrm{m}}$, stress response is faster and it is not biased by the evaluating person. Future work should not only continue to explore the capacity for stress detection of the PAM-imaging sensor but also soundly evaluate its economic value by comparing investments and benefits for each possible application.

Acknowledgements This project was supported by German government's Special Purpose Fund held at Landwirtschaftliche Rentenbank and the Federal Institution of Agriculture and Nutrition (BLE). We thank Jörg Kolbowski for the software developments. Furthermore, we thank Daniel Seitz, Melina Becker and Johannes Schlichting for their scientific studies. A very special thank is due to Alexandra Heyn for her technical support.

Funding Open Access funding enabled and organized by Projekt DEAL.

Open Access This article is licensed under a Creative Commons Attribution 4.0 International License, which permits use, sharing, adaptation, distribution and reproduction in any medium or format, as long as you give appropriate credit to the original author(s) and the source, provide a link to the Creative Commons licence, and indicate if changes were made. The images or other third party material in this article are included in the article's Creative Commons licence, unless indicated otherwise in a credit line to the material. If material is not included in the article's Creative Commons licence and your intended use is not permitted by statutory regulation or exceeds the permitted use, you will need to obtain permission directly from the copyright holder. To view a copy of this licence, visit http://creativecommons.org/licenses/by/4.0/.

\section{References}

Abbaspoor, M., \& Streibig, J. C. (2005). Clodinafop changes the chlorophyll fluorescence induction curve. Weed Science, 53, 1-9.

Abdi, H., \& Williams, L. J. (2010). Tukey's honestly significant difference (HSD) test. In N. J. Salkind (Ed.), Encyclopedia of research design (pp. 853-855). Thousand Oaks, CA: Sage.

Baker, N. R. (2008). Chlorophyll fluorescence: A probe of photosynthesis in vivo. Annual Review of Plant Biology, 59, 89-113.

Bauriegel, E., \& Herppich, W. B. (2014). Hyperspectral and chlorophyll fluorescence imaging for early detection of plant diseases, with special reference to Fusarium spec. infections on wheat. Agriculture. https://doi.org/10.3390/agriculture4010032

Belfry, K. D., Soltani, N., Brown, L. R., \& Sikkema, P. H. (2015). Tolerance of identity preserved soybean cultivars to preemergence herbicides. Canadian Journal of Plant Science, 95, 719-726.

Bigot, A., Fontaine, F., Clément, C., \& Vaillant-Gaveau, N. (2007). Effect of the herbicide flumioxazin on photosynthetic performance of grapevine (Vitis vinifera L.). Chemosphere, 67, 1243-1251.

Blackburn, G. A. (2006). Hyperspectral remote sensing of plant pigments. Journal of Experimental Botany, $58,855-867$.

Follak, S., \& Hurle, K. (2004). Recovery of non-target plants affected by airborne bromoxynil-octanoate and metribuzin. Weed Research, 44, 142-147.

Gamon, J. A., Penuelas, J., \& Field, C. B. (1992). A narrow-waveband spectral index that tracks diurnal changes in photosynthetic efficiency. Remote Sensing of Environment, 41, 35-44.

Gerhards, R., Gutjahr, C., Weis, M., Keller, M., Sökefeld, M., Möhring, J., et al. (2011). Using precision farming technology to quantify yield effects attributed to weed competition and herbicide application. Weed Research, 52, 6-15.

Govender, M., Dye, P. J., Weiersbye, I. M., Witkowski, E. T. F., \& Ahmed, F. (2009). Review of commonly used remote sensing and ground-based technologies to measure plant water stress. Water SA, $35,741-752$. 
Hankamer, B., \& Barber, J. (1997). Structure and membrane organization of photosystem II in green plants. Annual Review of Plant Physiology and Plant Molecular Biology, 48, 641-671.

Heap, I. (2014). Global perspective of herbicide-resistant weeds. Pest Management Science, 70, 1306-1315.

HRAC. (2020). Global classification lookup. Retrieved 29 Sept 2020 from https://hracglobal.com/tools/ classification-lookup.

Huberty, C. J., \& Olejnik, S. (2006). Applied MANOVA and discriminant analysis. New York, USA: Wiley.

Jin, Z. L., Zhang, F., Ahmed, Z. I., Rasheed, M., Naeem, M. S., Ye, Y. F., et al. (2010). Differential morphological and physiological responses of two Brassica species to a new herbicide ZJ0273 used in rapeseed fields. Pesticide Biochemistry and Physiology, 98, 1-8.

Kautsky, H., \& Hirsch, A. (1931). Neue Versuche zur Kohlenstoffassimilation (New experiments on carbon assimilation). Naturwissenschaften, 19, 964.

Kitajima, M., \& Butler, W. L. (1975). Quenching of chlorophyll fluorescence and primary photochemistry in chloroplasts by dibromothymoquinone. Biochimica et Biophysica Acta, 376, 105-115.

Knipling, E. B. (1970). Physical and physiological basis for the reflectance of visible and near-infrared radiation from vegetation. Remote Sensing of Environment, 1, 155-159.

Krause, H. G. (1994). Photoinhibition induced by low temperatures. In N. R. Baker \& J. R. Bowyer (Eds.), Photoinhibition of photosynthesis. From molecular mechanisms to the field (pp. 331-348). Oxford, UK: BIOS Scientific Publishers.

Li, H., Wang, P., Weber, J. F., \& Gerhards, R. (2018). Early identification of herbicide stress in soybean (Glycine max.(L.) Merr) using chlorophyll fluorescence imaging technology. Sensors, 18, 13. https ://doi.org/10.3390/s18010021

Lindenthal, M., Steiner, U., Dehne, H.-W., \& Oerke, E.-C. (2005). Effect of downy mildew development on transpiration of cucumber leaves visualized by digital infrared thermography. Phytopathology, 95, 233-240.

Loll, B., Kern, J., Saenger, W., Zouni, A., \& Biesiadka, J. (2005). Towards complete cofactor arrangement in the $3.0 \AA$ resolution structure of photosystem II. Nature, 438, 1040-1044.

Lowe, A., Harrison, N., \& French, A. P. (2017). Hyperspectral image analysis techniques for the detection and classification of the early onset of plant disease and stress. Plant Methods, 13, 80. https:// doi.org/10.1186/s13007-017-0233-z

Macinnis-Ng, C. M. O., \& Ralph, P. J. (2003). Short-term response and recovery of Zostera capricorni photosynthesis after herbicide exposure. Aquatic Botany, 76, 1-15.

Oerke, E. C., \& Steiner, U. (2010). Potential of digital thermography for disease control. In E. C. Oerke, R. Gerhards, G. Menz, \& R. A. Sikora (Eds.), Precision crop protections-The challenge and use of heterogeneity (pp. 167-182). Dordrecht, Netherlands: Springer.

Pascua, J. A. A., Prado, A. J. A., Solis, B. R. B., Cid-Andres, A. P., \& Cambiador, C. J. B. (2019). Trends in fabrication, data gathering, validation, and application of molecular fluorometer and spectrofluorometer. Spectrochimica Acta Part A: Molecular and Biomolecular Spectroscopy. https ://doi.org/10.1016/j.saa.2019.02.061

Peteinatos, G., Korsaeth, A., Berge, T. W., \& Gerhards, R. (2016). Using optical sensors to identify water deprivation, nitrogen shortage, weed presence and fungal infestation in wheat. Agriculture, 6 , 24. https://doi.org/10.3390/agriculture6020024

Pospíšil, P., Skotnica, J., \& Nauš, J. (1998). Low and high temperature dependence of minimum $\mathrm{F}_{\mathrm{o}}$ and $\mathrm{F}_{\mathrm{m}}$ chlorophyll fluorescence in vivo. Biochimica et Biopysica Acta, 1363, 95-99.

Poudyal, D., Rosenqvist, E., \& Ottosen, C. O. (2019). Phenotyping from lab to field-tomato lines screened for heat stress using $F_{\mathrm{v}} / F_{\mathrm{m}}$ maintain high fruit yield during thermal stress in the field. Functional Plant Biology, 46, 44-55.

Rosenqvist, E., \& van Kooten, O. (2003). Chlorophyll fluorescence: A general description and nomenclature. In J. R. DeEll \& P. M. A. Toivonen (Eds.), Practical applications of chlorophyll fluorescence in plant biology (pp. 31-37). Kluwer, Dordrecht, Netherlands: Springer.

Rouse, J.W., Haas, R.H., Schell, J.A., \& Deering, D.W. (1973). Monitoring the vernal advancement and retrogradiation (green waved effect) of natural vegetation. Technical Report (p. 112), Washington, DC: NASA.

Salzman, F. P., \& Renner, K. A. (1992). Response of soybean to combinations of clomazone, metribuzin, linuron, alachlor, and atrazine. Weed Technology, 6, 922-929.

Schreiber, U., Bilger, W., \& Neubauer, C. (1995). Chlorophyll fluorescence as a nonintrusive indicator for rapid assessment of in vivo photosynthesis. In E. D. Schulze \& M. M. Caldwell (Eds.), Ecophysiology of photosynthesis (p. 100). Berlin, Heidelberg, Germany: Springer.

Sitte, P., Ziegler, H., Ehrendorfer, F., \& Bresinsky, A. (1998). Lehrbuch der Botanik für Hochschulen (Botany textbook for universities). Stuttgart, Germany: Gustav Fischer. 
Smith, A. E., \& Wilkinson, R. E. (1974). Differential absorption, translocation and metabolism of metribuzin [4-amino-6-tertbutyl- 3-(metbylthio)-as-triazine-5(4H)one] by soybean cultivars. Journal of Plant Physiology, 32, 253-257.

Stirbet, A., \& Govindjee, G. (2011). On the relation between the Kautsky effect (chlorophyll a fluorescence induction) and photosystem II: Basics and applications of the OJIP fluorescence transient. Journal of Photochemistry and Photobiology B: Biology, 104, 236-257.

Trissl, H.-W., Gao, Y., \& Wulf, K. (1993). Theoretical fluorescence induction curves derived from coupled differential equations describing the primary photochemistry of photosystem II by an excitonradical pair equilibrium. Biophysical Journal, 64, 974-988.

Vadivambal, R., \& Jayas, D. S. (2011). Applications of thermal imaging in agriculture and food industry-A review. Food Bioprocess Technology, 4, 186-199.

Wang, P., Peteinatos, G. G., Li, H., \& Gerhards, R. (2016). Rapid in-season detection of herbicide resistant Alopecurus myosuroides using a mobile fluorescence imaging sensor. Crop Protection, 89, 170-177.

Wang, P., Peteinatos G.G., \& Gerhards, R. (2017). In field identification of herbicide resistant Apera spicaventi using chlorophyll fluorescence. In Taylor, J.A., Cammarano, D., Prashar, A., Hamilton, A., (Eds.) Proceedings of the 11th European conference on precision agriculture. Advances in Animal Bioscience: Precision Agriculture, 8, 283-287.

Wang, P., Peteinatos, G. G., Li, H., Brändle, F., Pfündel, E., Drobny, H. G., et al. (2018). Rapid monitoring of herbicide-resistant Alopecurus myosuroides Huds. using chlorophyll fluorescence imaging technology. Journal of Plant Diseases and Protection, 125, 187-195.

Weber, J. F., Kunz, C., Peteinatos, G. G., Santel, H.-J., \& Gerhards, R. (2017). Utilization of chlorophyll fluorescence imaging technology to detect plant injury by herbicides in sugar beet and soybean. Weed Technology, 31, 523-535.

Wilson, R. G. (1999). Response of nine sugar beet (Beta vulgaris) cultivars to postemergence herbicide application. Weed Technology, 13, 25-29.

Wilson, R. G., Yonts, C. D., \& Smith, J. A. (2002). Influence of glyphosate and glufosinate on weed control and sugar beet (Beta vulgaris) yield in herbicide-tolerant sugar beet. Weed Technology, 16, 66-73.

Xue, J., \& Su, B. (2017). Significant remote sensing vegetation indices: A review of developments and applications. Journal of Sensors. https://doi.org/10.1155/2017/1353691

Publisher's Note Springer Nature remains neutral with regard to jurisdictional claims in published maps and institutional affiliations. 